\title{
Management of tibial non-unions: Prospective evaluation of a comprehensive treatment algorithm
}

\author{
N Ferreira ${ }^{1}$ BSc, MBChB, FC Orth(SA), MMed(Orth), PhD \\ LC Marais ${ }^{1}$ MBChB, FCS Orth(SA), MMed(Ortho), PhD \\ C Aldous² BSc, BSc(Hons), MSc, PhD
}

${ }^{1}$ Tumour, Sepsis and Reconstruction Unit, Department of Orthopaedic Surgery, Grey's Hospital,

Nelson R. Mandela School of Medicine, University of KwaZulu-Natal

${ }^{2}$ Medical Research Scientist, School of Clinical Medicine, College of Health Sciences, University of KwaZulu-Natal

\author{
Corresponding author: \\ Dr Nando Ferreira \\ Department of Orthopaedic Surgery \\ Grey's Hospital \\ 3201 Pietermaritzburg \\ KwaZulu-Natal \\ South Africa \\ Tel: +27338973000 \\ Email: Nando.Ferreira@kznhealth.gov.za
}

\begin{abstract}
Tibial non-unions represent a spectrum of conditions and are challenging to treat. The optimal management remains unclear despite the frequency with which these diagnoses are encountered. We developed a tibial nonunion treatment algorithm following two retrospective audits of our patient outcomes and evaluated this algorithm in this prospective series. Thirty-seven consecutive patients with 39 uninfected tibial non-unions were treated according to our proposed treatment algorithm. There were 30 men and seven women with a mean age of 34 years. Twenty-three non-unions were classified as stiff hypertrophic, ten mobile atrophic and four mobile oligotrophic. Two non-unions were classified as type B1 defect non-unions. Bony union was achieved after the initial treatment in 37/39 (94.8\%) tibias. Two patients had failure of treatment. These patients presented with progressive deformity after the external fixator was removed. One of these patients was successfully retreated according to the tibial non-union treatment algorithm. This resulted in final bony union after treatment in 38/39 $(97.4 \%)$ tibias. Our proposed treatment algorithm appears to produce high union rates across a diverse group of tibial non-unions. These conditions however, remain difficult to treat and should be referred to specialist units where advanced reconstructive techniques are practised on a regular basis.
\end{abstract}

Key words: Ilizarov, hexapod, non-union, circular external fixator

http:/ / dx.doi.org/10.17159/2309-8309/2016/v15n1a6

\section{Introduction}

Non-unions are frequent complications of tibial shaft fractures and their management remains a challenge for orthopaedic surgeons. ${ }^{1}$ Quoted incidences range between $8 \%$ and $13 \%$, but despite the frequency with which they are encountered treatment has not been standardised nor based on large randomised control trials. ${ }^{2-5}$ As such, treatment failure rates of up to $20 \%$ have been reported in the literature. $^{6}$

Non-unions can be classified as atrophic or hypertrophic, mobile or stiff, with or without deformity, with or without bone defects and as infected or not. ${ }^{6-11}$ This diversity in non-union pathophysiology and presentation complicates their management, as each subgroup often requires radically different treatment strategies. ${ }^{6,11-13}$ The management is further complicated by delays in referral that contribute to loss of limb function secondary to muscle atrophy, joint contractures and disuse osteopaenia. ${ }^{3,14}$ Inappropriate management may cause further delays and additional risk to limb integrity. ${ }^{15}$ Adopting the appropriate treatment strategy is of vital importance and should promote union while simultaneously allowing functional rehabilitation.

We report the results of the management of uninfected tibial non-unions treated according to our proposed tibial non-union treatment algorithm (Figure 1). 


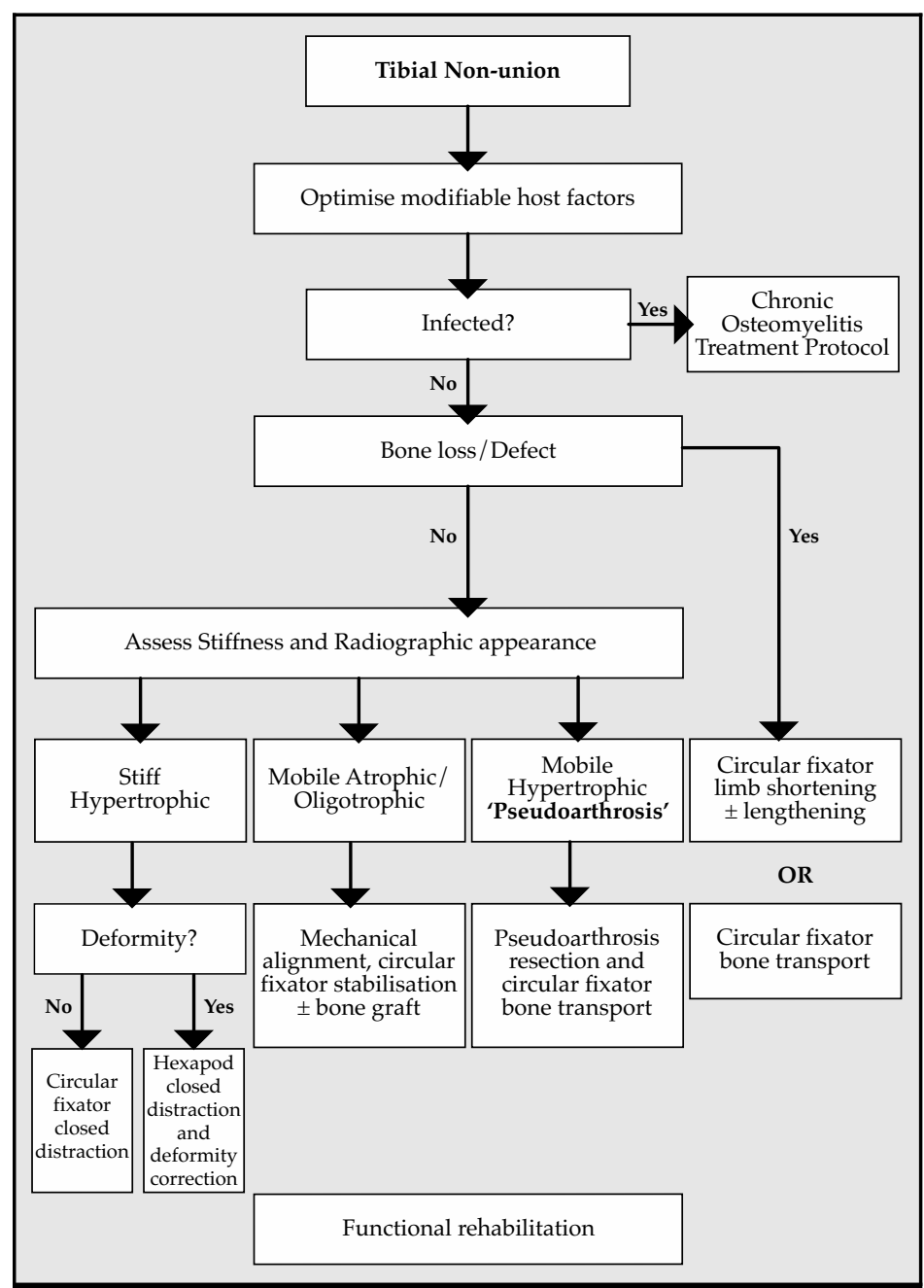

Figure 1. Tibial non-union treatment algorithm

\section{Materials and methods}

Between January 2014 and December 2014, all patients who presented with uninfected tibial non-unions were treated according to our proposed tibial non-union treatment algorithm. This algorithm was developed based on results from two retrospective audits of patients with tibial non-unions who were treated at our institution between January 2010 and December 2013. Thirty-eight patients with 40 non-unions were included. One patient was excluded because his treatment was ongoing at the time of analysis. This patient had a defect non-union undergoing bone transport.

A physical, laboratory and radiographic evaluation were performed on all patients as per departmental protocol. Any modifiable risk factors that were identified were optimised prior to surgical intervention. These included cessation of smoking, optimal glycaemic control in diabetics and the commencement of highly active antiretroviral therapy (HAART) for HIV-positive patients with low $\mathrm{CD} 4$ counts.
Partial fibula resection was performed in all cases at the time of the index procedure. Resection was performed under tourniquet control and at the level of the fibular deformity if present. Direct surgical approach between the peroneal and soleus muscles was made. The fibula was exposed by sub-periosteal dissection, and a small oscillating saw was used to resect approximately $1 \mathrm{~cm}$ of fibula to prevent early fibular consolidation. Fascia and skin were closed in layers over a drain. The tourniquet was deflated for the remainder of the operation.

Mobile atrophic and oligotrophic non-unions were stabilised with Ilizarov-type circular external fixation. These frames were applied using a standard trauma frame' construct and application technique. ${ }^{16}$ After mechanical alignment and stable fixation, the non-union site was manually compressed and the frame statically locked. The addition of iliac crest autograft was only considered if the non-union site had a diameter less than $50 \%$ of the normal bone diameter. This was required in four patients.

Defect non-unions were treated with standard 'transport frame' constructs. These frames consisted of ring blocks proximal and distal to a fifth transport ring. The ring blocks were designed in such a way as to allow a metaphyseal osteotomy to generate a bony transport segment. After a latency period of 7 to 10 days bone transport was started at a rate and rhythm of $0.25 \mathrm{~mm}$ four times per day. A docking procedure in the form of a Phemister autograft was performed for all patients. ${ }^{17}$

Stiff hypertrophic non-unions were treated with closed gradual distraction through the use of hexapod external fixators. These fixators were applied using the 'rings first' method and the non-union site was left undisturbed. After post-operative radiographic evaluation, a correction programme was generated through the online software and distraction was effected at a rate of $1 \mathrm{~mm}$ per day at the apex of deformity.

Pin-track management occurred according to our standard protocol that encompasses a meticulous intraoperative insertion technique and a rigorous postoperative pin-care regimen that included twice-daily cleaning with an alcoholic solution of chlorhexidine. ${ }^{18,19}$ Early functional rehabilitation was encouraged with the assistance of a physiotherapist. This entailed adjacent joint mobilisation and weight bearing followed by normalisation of gait pattern and functional use.

Outpatient follow-up was scheduled at two-weekly intervals until a robust rehabilitation routine was established. Thereafter the follow-up was increased to fourweekly intervals. Fixator removal was considered once tricortical consolidation was seen. At this juncture, a staged 'trial of union' protocol was initiated. First the external fixator was completely dynamised and the union site manually stressed. If this did not cause any pain or deformity the patient was instructed to weight bear. If the patients were able to walk without pain, they were allowed to return home with a fully dynamised frame and 
encouraged to mobilise full weight bearing for a period of two weeks. Repeat radiographs at follow-up were compared with radiographs from two weeks before. If no deformity occurred during this trial period, union was confirmed and the external fixator was removed. All patients were followed up clinically and radiologically one month after frame removal. Any changes in angulation from previous visits were identified as a failure of treatment.

\section{Results}

The medical records and serial radiographs of all 37 patients were reviewed. The study population consisted of 30 men and seven women with 39 tibial non-unions with a mean age of 34 years ranging from 18 to 73 years (Table I). Two patients were treated for bilateral tibial non-unions. Twenty-three non-unions were classified as stiff hypertrophic, ten mobile atrophic and four mobile oligotrophic according to the Ilizarov and Weber and Cech classifications. ${ }^{78}$ The remaining two cases were type B1 defect nonunions according to the Paley classification. ${ }^{9}$ These patients had $3 \mathrm{~cm}$ and $6 \mathrm{~cm}$ defects respectively.

Open fractures were the initial injury in the majority of cases $(n=27)$. Fifteen fractures were initially graded as Gustilo-Anderson IIIB, 11 as Gustilo-Anderson IIIA and one as a Gustilo-Anderson II open fractures. ${ }^{20,21}$ Two patients sustained fractures following gunshots. One patient developed a mid-shaft tibial non-union following a derotation osteotomy. The remaining nine cases were closed fractures that were treated with a plaster of Paris cast in four cases, tibial nail in four cases and a circular external fixator in the remaining case. Duration of nonunion ranged from 6 to 48 months since the initial injury, with a mean of 13 months (standard deviation [SD] 9.6 months).

Risk factors for non-union development were identified in $33 / 37(89 \%)$ patients. These included open fractures $(\mathrm{n}=27)$, smoking $(\mathrm{n}=17)$, diabetes $(\mathrm{n}=1)$, hypothyroidism $(n=1)$, oblique distal third tibia fracture $(n=1)$, and internal fixation (nail) with a fixed fracture gap $(n=4)$. The remaining four patients all had closed fractures and no obvious risk factors for non-union formation. Seven patients were HIV-positive (19\%). Two of these patients had bilateral tibial non-unions. Four HIV-positive patients with a mean CD4 count of 872 cells $/ \mathrm{mm}^{3}$ (range 581-1056) were on HAART treatment while the remaining three patients with a mean CD4 count of 325 cells $/ \mathrm{mm}^{3}$ (range 260-433) were treatment naive.

The Ilizarov external fixator (Smith \& Nephew, Memphis, TN) was used for five, and the Truelok external fixator (Orthofix, Verona, Italy) for nine mobile atrophic and oligotrophic non-unions. The average time in external fixator was 32 weeks, ranging from 13 to 53 weeks. Stiff hypertrophic non-unions were treated with the Taylor Spatial Frame (TSF) (Smith \& Nephew, Memphis, TN) in seven and the Truelok-Hex (TL-Hex) (Orthofix, Verona, Italy) in 16 cases. The average time in external fixator was 25 weeks, ranging from 13 to 60 weeks. Both patients with defect non-unions were treated with the Truelok external fixator (Orthofix, Verona, Italy). These patients spent 31 and 66 weeks in external fixators respectively.

Bony union was achieved after the initial treatment in $37 / 39(94.8 \%)$ tibias. Two patients had failure of treatment. These patients presented with progressive deformity after the external fixator was removed. Failure after initial treatment was judged to be the result of early external fixator removal and underlines the difficulty of confirming

\section{Table I: Details of results}

\begin{tabular}{|c|c|c|c|}
\hline Type of non-union & $\begin{array}{c}\text { Mobile } \\
\text { atrophic/oligotrophic }\end{array}$ & $\begin{array}{c}\text { Stiff } \\
\text { hypertrophic }\end{array}$ & Defect \\
\hline Patients & 13 & 22 & 2 \\
\hline Males & $11^{\mathrm{a}}$ & $17^{\mathrm{b}}$ & 2 \\
\hline Females & 2 & 5 & - \\
\hline Mean age (years) & $31(18-59)$ & $38(18-66)$ & $23(20-27)$ \\
\hline Average time to non-union surgery (months) & $11(6-18)$ & $15(6-48)$ & $7(6-8)$ \\
\hline \multicolumn{4}{|l|}{ Fixator } \\
\hline Ilizarov & 5 & - & - \\
\hline Truelok & 9 & - & 2 \\
\hline Taylor Spatial Frame & - & 7 & - \\
\hline Truelok-Hex & - & 16 & - \\
\hline Average healing time (weeks) & $32(13-53)$ & $25(13-60)$ & $48(31-66)$ \\
\hline \multicolumn{4}{|l|}{ Treatment strategy } \\
\hline Compression & 14 & - & - \\
\hline Distraction & - & 23 & - \\
\hline Bone Transport & - & - & 2 \\
\hline Iliac autograft & 5 & 0 & 2 \\
\hline
\end{tabular}


union in certain cases. One of these patients was successfully retreated according to the tibial non-union treatment algorithm. This resulted in final bony union after treatment in 38/39 (97.4\%) tibias. The remaining patient was a heavy alcohol user and smoker who sustained an open tibia fracture with a resultant non-union. Retreatment will be considered once the patient has moderated his alcohol intake and stopped smoking.

Leg lengths after union were equalised to within $1 \mathrm{~cm}$ of the contralateral side in $37(94.8 \%)$ tibias. Alignment with deformity less than $5^{\circ}$ was achieved in $36(92.3 \%)$ tibias. The remaining three patients had $5^{\circ}$ valgus in two patients and $8^{\circ}$ procurvatum with $2 \mathrm{~cm}$ shortening in one patient.

Pin-track infection was the most common complication experienced and occurred in $7 / 39(17.9 \%)$ cases. The majority of these infections was minor according to the Checketts and Otterburn classification and responded to local pin-track care and oral antibiotics. ${ }^{22}$ One patient developed a grade VI infection. This patient presented with a non-healing pin site four weeks after external fixator removal. He was subsequently treated with debridement of the pin track using the Versajet Hydrosurgery system (Smith \& Nephew, Memphis, TN) and healing occurred without any further complications. ${ }^{23}$

\section{Discussion}

The optimal treatment of tibial non-unions remains to be established but several authors have outlined the principles for the ideal treatment. Kanellopoulus considered the ability to simultaneously address axial deviations, shortening, bone loss, poor blood supply and achieve union without further compromise of the softtissue envelope as the ideal treatment. ${ }^{15} \mathrm{He}$ emphasised that this should be achieved while simultaneously not only maintaining function, but improving it. ${ }^{15}$ Gershuni regarded the restitution of bony continuity, correction of alignment in all planes, maintenance and recovery of function and limitation of further complications as the ideal management strategy. ${ }^{24}$ Giannoudis recently introduced the 'Diamond concept' to the management of nonunions. ${ }^{25}$ This approach attempts to address all factors implicated, namely the cellular environment, growth factors, bone matrix and mechanical stability. We consider the optimisation of modifiable host factors, mechanical alignment, stable fixation, biological stimulation and early functional rehabilitation the five pillars of non-union management.

Biological stimulation can be achieved in several ways. Autogenous bone graft and bone morphogenic proteins (BMPs) remain the most frequently used method to stimulate healing, especially in atrophic non-unions. ${ }^{11,12,26}$ Biological stimulation can also be achieved by creating the ideal mechanical environment to support bone formation: the concept of mechano-biology. ${ }^{27-32}$ Ilizarov further demonstrated the tension stress effect to stimulate tissue growth through distraction histogenesis. ${ }^{33-35}$
Mechano-biology refers to the ability of the body's physiological processes to respond to the mechanical environment and is the foundation of all non-union management. ${ }^{27,30}$ Ilizarov stated that functional load determines the structure, shape and volume of a limb. This is due to a local increase in blood flow during functional use that aids in tissue growth. ${ }^{29}$ Mechanical stimulation also directly influences bone biology on a cellular level by stimulating the proliferation and differentiation of osteoblasts..$^{29,31}$ Mechanical force application patterns, loading magnitude and frequency also affect bone healing on a biochemical level. ${ }^{31}$ The rates of synthesis and degradation of extracellular matrix components are affected by force application patterns. Loading magnitude affects cell size through increased amounts of intermediate filaments and glycogen particles while changes in loading frequency can alter mRNA synthesis of anabolic and catabolic genes. ${ }^{31}$ Aggrecan gene expression is increased in response to mechanical stimulation and leads to an increased proteoglycan scaffold for type II collagen. ${ }^{29}$ Mechanical stimulation has further benefits in terms of union site remodelling as a result of piezo-electrical charges that are generated in response to mechanical stresses. Osteoblasts on the compressive side are stimulated as a result of electronegative charges while osteoclasts are activated by electropositive charges on the tension side. ${ }^{31,36}$ These mechano-biological processes can be exploited in non-union management to produce union even in the setting of apparent biological inactivity of atrophic non-unions. This was shown in our results where eight out of $13(62 \%)$ atrophic and oligotrophic non-unions healed without the need for autogenous bone graft (Figures $2 a, 2 b, 2 c$ ).

The effectiveness of distracting stiff hypertrophic nonunions can be explained by the interfragmentary strain theory of Perren. ${ }^{37,38}$ This states that fracture displacement $(\delta \mathrm{L})$ in relation to the initial fracture gap (L) produces strain $(\delta \mathrm{L} / \mathrm{L})$ that can either induce bone formation and union (strain $<2 \%$ ) or induce bone resorption with resultant non-union (strain $>10 \%) .{ }^{37}$ Distracting stiff nonunions has a two-fold effect on decreasing interfragmentary strain. First, the tension caused by distracting an inherently stiff environment combined with stable fixation decreases interfragmentary motion $(\delta \mathrm{L})$. Secondly, distraction of the non-union increases the fracture gap (L). This results in an overall reduction of strain to within tolerable limits for bone formation in the distraction gap. The clinical implications of this theory are clearly illustrated in our series where 22 out of $23(95.6 \%)$ stiff tibial non-unions healed after closed distraction, sometimes with exuberant callus formation (Figures $3 a, 3 b, 3 c$ ).

Circular external fixators are ideally suited to provide stability for non-union management..$^{39,40}$ Their use, especially in tibial malunions and non-unions has gained popularity in recent years. ${ }^{910,14,15,41-44}$ These fixators have the ability to provide stability against translation and rotation in the coronal and sagittal planes while maintaining a degree of axial micro motion to stimulate bone formation..$^{45-48}$ 


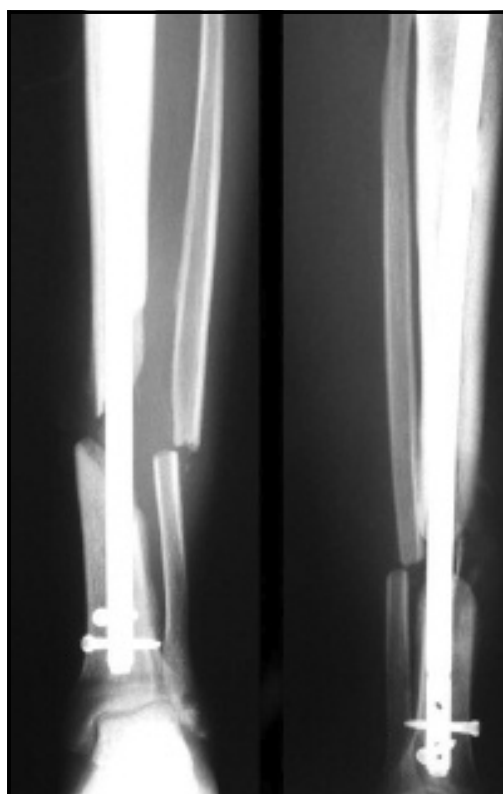

Figure 2a. Antero-posterior and mediolateral radiograph of tibial non-union 10 months after intramedullary nail
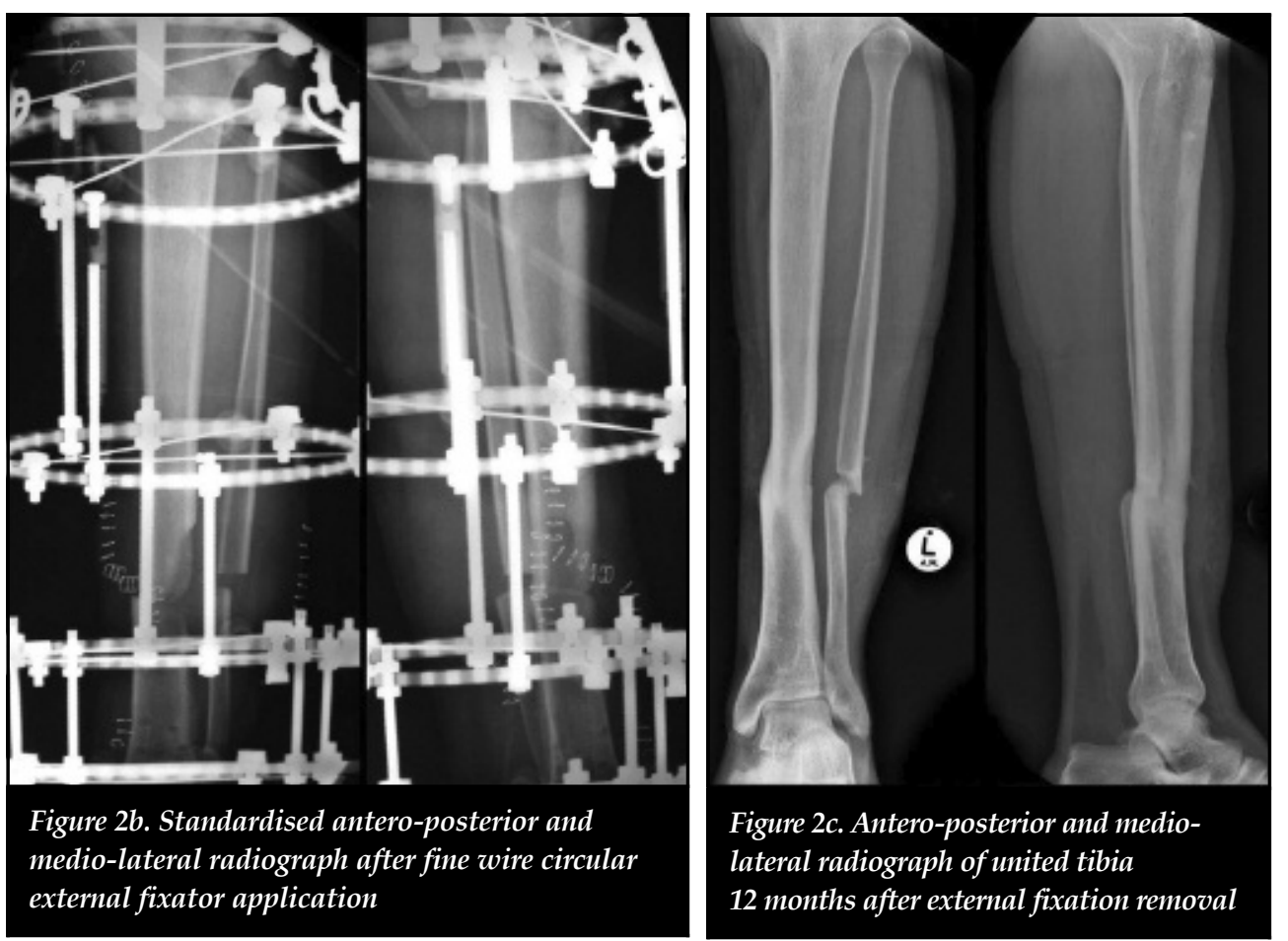

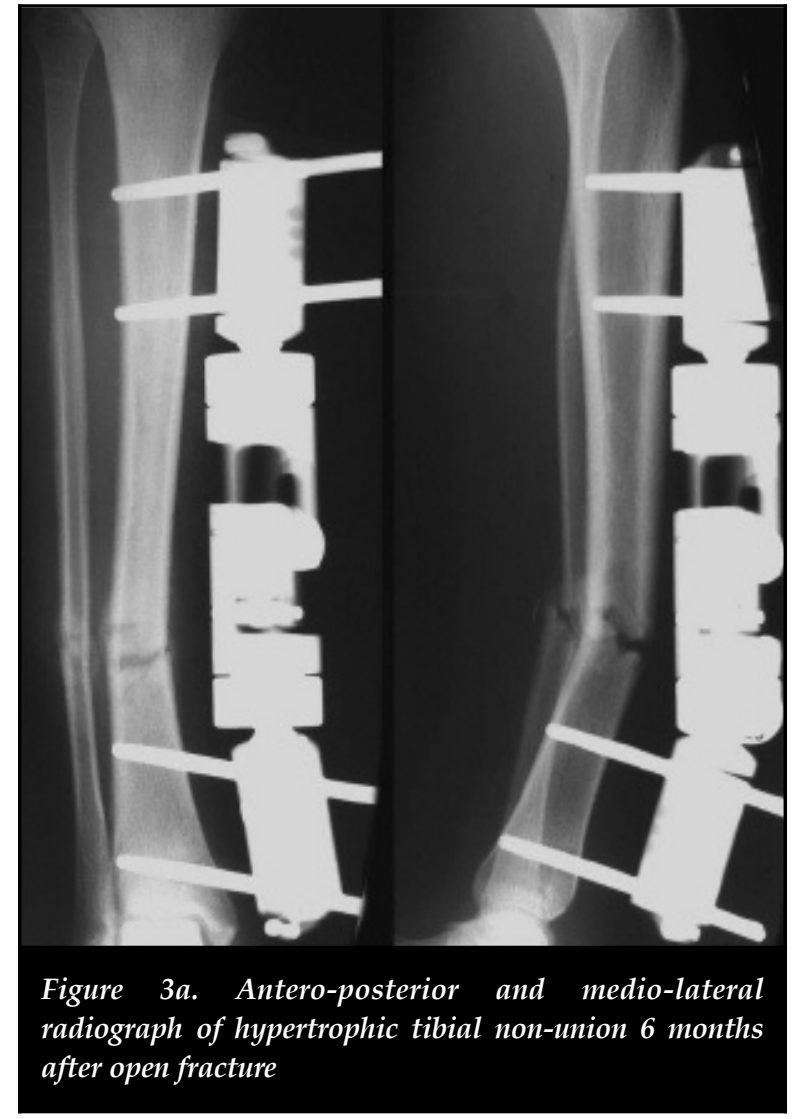

Circular fixators can also be applied with minimal iatrogenic disruption of the local biological environment and can be designed to correct mechanical alignment, either acutely or gradually, as with mobile and stiff non-unions respectively. Furthermore, the three-dimensional stability that these fixators provide allows early functional rehabilitation without the need for any period of protected weight bearing after non-union treatment. Although 37 patients represent a large study population for tibial non-union management, the patient numbers included in each subgroup are relatively few.

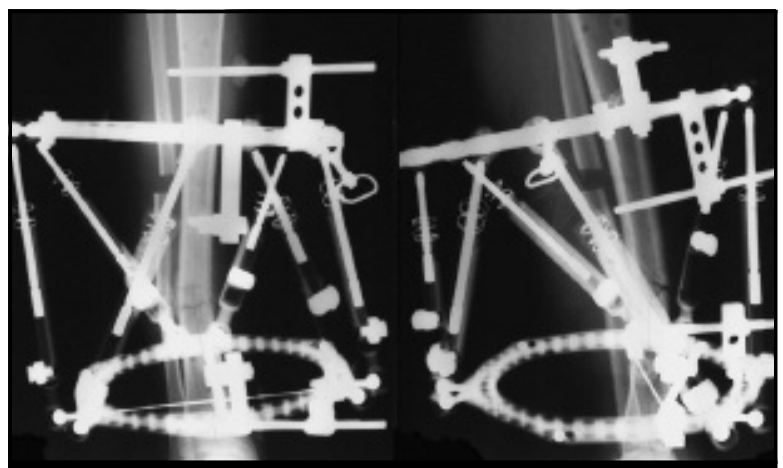

Figure 3b. Standardised antero-posterior and mediolateral radiograph after hexapod frame application 


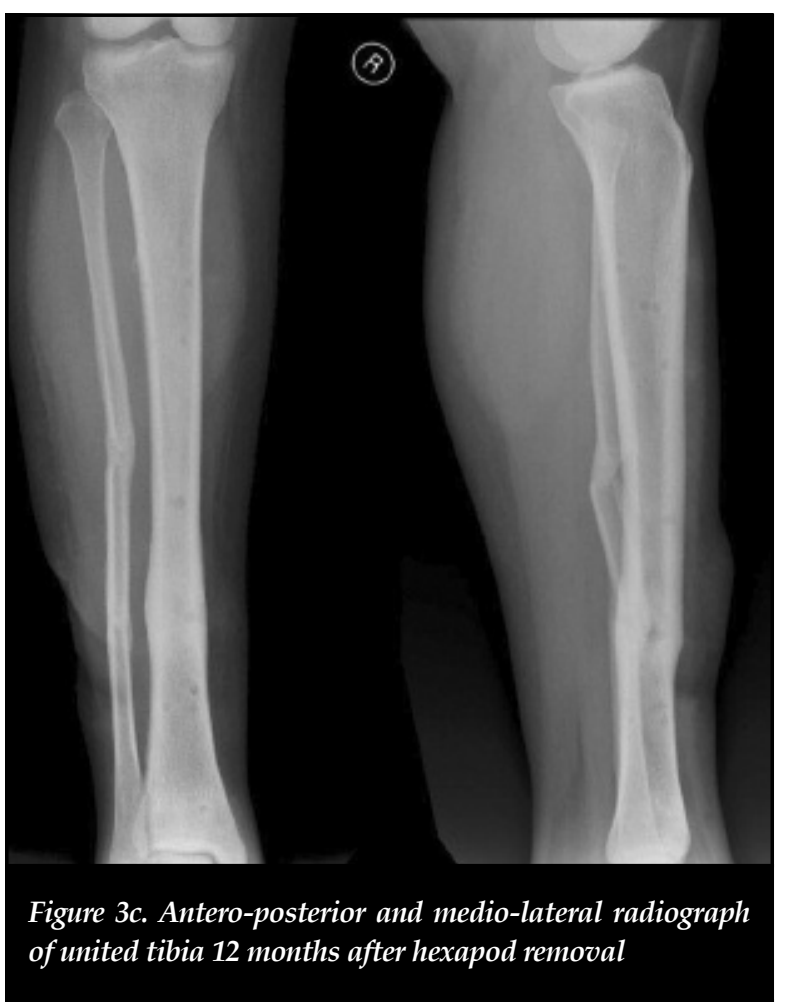

This research could represent a pilot study for the evaluation of our proposed treatment algorithm, and future validation of this treatment with larger study groups in different study locations should be conducted. The lack of control groups for each treatment strategy is a further limitation and could be addressed in future research.

In conclusion, our proposed tibial non-union treatment algorithm appears to produce high union rates across a diverse group of tibial non-unions. Although these results are encouraging in striving for a standardised treatment strategy for tibial non-unions, we still recommend that that these cases be referred to specialist units where these advanced reconstructive techniques are practised on a regular basis.

\section{Conflict of interest statement}

The authors declare that they have no conflict of interests, and that no financial support was received for this study.

\section{Ethical statement}

The study was approved by an institutional ethics committee (BE 086/14) and performed in accordance with the Ethical standards of the 1964 Declaration of Helsinki as revised in 2000 .

\section{Authors' contributions}

All three authors made contributions toward the conception and design of the research, acquisition of data and drafting of the manuscript. The final manuscript was read and approved by all the authors.

\section{References}

1. Feldman DS, Shin SS, Madan SS, Koval KJ. Correction of tibial malunion and non-union with six-axis analysis deofmrity correction using the Taylor Spatial Frame. J Orthop Trauma. 2003;17:549-54.

2. Audige L, Griffin D, Bhandari M, Kellam J, Ruedi TP. Path analysis of factors for delayed healing and nonunion in 416 operatively treated tibial shaft fractures. Clin Orthop Relat Res. 2005;438:221-32.

3. Antonova E, Kim Le T, Burge R, Mershon J. Tibia Shaft fracture - costly burden of nonunions. BMC Musculoskelet Disord. 2013;14:42.

4. Fong K, Truong V, Foote CJ, Petrisor B, Williams D, Ristevski $\mathrm{B}$, et al. Predictors of nonunion and reoperation in patients with fractures of the tibia: an observational study. BMC Musculoskelet Disord. 2013;14:103. PubMed PMID: 23517574. Pubmed Central PMCID: 3614478.

5. Mills LA, Simpson AH. The relative incidence of fracture non-union in the Scottish population (5.17 million): a 5-year epidemiological study. BMJ open. 2013;3(2). PubMed PMID: 23396560. Pubmed Central PMCID: 3586107.

6. Calori GM, Phillips M, Jeetle S, Tagliabue L, Giannoudis PV. Classification of non-union: need for a new scoring system? Injury. 2008;39(Suppl 2):S59-63. PubMed PMID: 18804575.

7. Judet J, Judet R. L'osteogene et les retards de consolidation et les pseudarthroses des os longs. Huitieme Congress SICOT 1960:15.

8. Weber B, Cech O, editors. Pseudarthrosis. Bern, Switzerland: Hans Huber; 1976.

9. Paley D, Catagni MA, Argnani F, Villa A, Benedetti GB, Cattaneo R. Ilizarov treatment of tibial nonunions with bone loss. Clin Orthop Relat Res. 1989;(241):146-65. PubMed PMID: 2924458.

10. Paley D. Treatment of tibial nonunion and bone loss with the Ilizarov technique. Instructional course lectures. 1990;39:185-97. PubMed PMID: 2186101.

11. Wu CC, Chen WJ. A revised protocol for more clearly classifying a nonunion. J Orthop Surg. 2000;8(1):45-52. PubMed PMID: 12468875.

12. Jones $C B$, Mayo KA. Nonunion treatment: iliac crest bone graft techniques. J Orthop Trauma. 2005;19(10 Suppl):S11-13. PubMed PMID: 16479216.

13. Megas P. Classification of non-union. Injury. 2005;36 Suppl 4:S30-37. PubMed PMID: 16291321.

14. Akhtar A, Shami A, Sarfraz M. Functional Outcome of Tibial Nonunion Treatment by Ilizarov Fixator. Ann Pak Inst Med Sci. 2012;8(3):188-91.

15. Kanellopoulos AD, Soucacos PN. Management of nonunion with distraction osteogenesis. Injury. 2006;37 Suppl 1:S51-5. PubMed PMID: 16574120.

16. Ferreira N, Mare PH, Marais LC. Circular external fixator application for midshaft tibial fractures: Surgical technique. SA Orthop J. 2012;11(4):39-42.

17. Phemister DB. Treatment of ununited fractures by onlay bone grafts without screw or tie fixation and without breaking down of the fibrous union. J Bone Joint Surg [Am]. 1947;29(4):946-60. PubMed PMID: 20270359.

18. Ferreira N, Marais LC. Prevention and management of external fixator pin track sepsis. Strat Traum Limb Recon. 2012;7(2):67-72. PubMed PMID: 22729940. Pubmed Central PMCID: 3535127. 
19. Ferreira N, Marais LC. Pin tract sepsis: incidence with the use of circular fixators in a limb reonstruction unit. $S A$ Orthop J. 2012;11(1):10-18.

20. Gustilo RB, Anderson JT. Prevention of infection in the treatment of one thousand and twenty-five open fractures of long bones: retrospective and prospective analyses. J Bone Joint Surg [Am]. 1976;58(4):453-58. PubMed PMID: 773941.

21. Gustilo RB, Mendoza RM, Williams DN. Problems in the management of type III (severe) open fractures: a new classification of type III open fractures. J Trauma. 1984;24(8):742-6. PubMed PMID: 6471139.

22. Checketts RG, MacEachem AG, Otterburn M. Pin track infection and the principles of pin site care. Orthofix External Fixation in Trauma and Orthopaedics. 2001:97-103.

23. Bibbo C, Brueggeman J. Prevention and management of complications arising from external fixation pin sites. J Foot Ankle Surg. 2010;49(1):87-92. PubMed PMID: 20123298.

24. Gershuni DH. Fracture nonunion. West J Med. 1989;150(6):689-90. PubMed PMID: 2750154. Pubmed Central PMCID: 1026720.

25. Calori GM, Giannoudis PV. Enhancement of fracture healing with the diamond concept: the role of the biological chamber. Injury. 2011;42(11):1191-93. PubMed PMID: 21596376.

26. Frolke JP, Patka P. Definition and classification of fracture non-unions. Injury. 2007;38(Suppl 2):S19-22. PubMed PMID: 17920413.

27. Ilizarov G, editor. Transosseous osteosynthesis. 1st ed. Berlin: Springer; 1992.

28. Carter DR, Beaupre GS, Giori NJ, Helms JA. Mechanobiology of skeletal regeneration. Clin Orthop Relat Res. 1998;355:S41-55. PubMed PMID: 9917625.

29. Bhandari M, Schemitsch E. Clinical advances in the treatment of fracture nonunion: the response to mechanical stimulation. Curr Opin Orthop. 2000;11:372-77.

30. Kloen P, Doty SB, Gordon E, Rubel IF, Goumans MJ, Helfet DL. Expression and activation of the BMP-signaling components in human fracture nonunions. J Bone Joint Surg [Am]. 2002;84-A(11):1909-18. PubMed PMID: 12429748.

31. Chen JC, Carter DR. Important concepts of mechanical regulation of bone formation and growth. Curr Opin Orthop. 2005;16:338-45.

32. Jagodzinski M, Krettek C. Effect of mechanical stability on fracture healing—an update. Injury. 2007;38(Suppl 1):S310. PubMed PMID: 17383483.

33. Ilizarov GA. The tension-stress effect on the genesis and growth of tissues. Part I. The influence of stability of fixation and soft-tissue preservation. Clin Orthop Relat Res. 1989;238:249-81. PubMed PMID: 2910611.

34. Ilizarov GA. The tension-stress effect on the genesis and growth of tissues: Part II. The influence of the rate and frequency of distraction. Clin Orthop Relat Res. 1989;239:263-85. PubMed PMID: 2912628.
35. Ilizarov GA. Clinical application of the tension-stress effect for limb lengthening. Clin Orthop Relat Res. 1990;250:8-26. PubMed PMID: 2403497.

36. Webb J, Tricker J. A review of fracture healing. Curr Orthop. 2000;14:457-63.

37. Perren SM. Physical and biological aspects of fracture healing with special reference to internal fixation. Clin Orthop Relat Res. 1979;138:175-96. PubMed PMID: 376198.

38. Perren SM. Evolution of the internal fixation of long bone fractures. The scientific basis of biological internal fixation: choosing a new balance between stability and biology. J Bone Joint Surg [Br]. 2002;84(8):1093-110. PubMed PMID: 12463652.

39. Paley D. Biomechanics of the Ilizarov external fixator. In Bianchi-Maiocchi A, Aronson J, Editors. Operative Principles of Ilizarov. Philadelphia: Williams \& Wilkins 1991:33-42.

40. Caja V, Kim W, Larsson S, E YC. Comparison of the mechanical performance of three types of external fixators: linear, circular and hybrid. Clin Biomech. 1995;10(8):401-406. PubMed PMID: 11415586.

41. Catagni MA, Guerreschi F, Holman JA, Cattaneo R. Distraction osteogenesis in the treatment of stiff hypertrophic nonunions using the Ilizarov apparatus. Clin Orthop Relat Res. 1994;301:159-63. PubMed PMID: 8156667.

42. Catagni, MA. (2009) Treatment of fractures, nonunions, and bone loss of the tibia with the Ilizarov method. (5th Edition) Il quadratino, Italy.

43. Feldman DS, Shin SS, Madan S, Koval KJ. Correction of tibial malunion and nonunion with six-axis analysis deformity correction using the Taylor spatial frame. $J$ Orthop Trauma. 2003;17(8):549-54.

44. Dujardyn D, Lammens J. Treatment of delayed union or non-union of the tibial shaft with partial fibulectomy and an Ilizarov frame. Acta orthop Belg. 2007;73:630-34.

45. Paley D, Fleming B, Catagni M, Kristiansen T, Pope M. Mechanical evaluation of external fixators used in limb lengthening. Clin Orthop Relat Res. 1990;250:50-57. PubMed PMID: 2293944.

46. Mullins MM, Davidson AW, Goodier D, Barry M. The biomechanics of wire fixation in the Ilizarov system. Injury. 2003;34(2):155-57. PubMed PMID: 12565025.

47. Hasenboehler E, Smith WR, Laudicina L, Philips GC, Stahel PF, Morgan SJ. Fatigue behavior of Ilizarov frame versus tibial interlocking nail in a comminuted tibial fracture model: a biomechanical study. J Orthop Surg Res. 2006;1:16. PubMed PMID: 17156471. Pubmed Central PMCID: 1702341.

48. Fragomen AT, Rozbruch SR. The mechanics of external fixation. HSS J. 2007;3(1):13-29. PubMed PMID: 18751766. Pubmed Central PMCID: 2504087.

This article is also available online on the SAOA website (www.saoa.org.za) and the SciELO website (www.scielo.org.za). Follow the directions on the Contents page of this journal to access it. 